\title{
DO CONTROLE INTERNO AO CONTROLE SOCIAL: A MÚLTIPLA ATUAÇÃO DA CGU NA DEMOCRACIA BRASILEIRA
}

\author{
FROM AUDITING TO SOCIAL CONTROL: THE MULTIPLE ACTION OF CGU IN THE BRAZILIAN DEMOCRACY
}

\begin{abstract}
RESUMO
O trabalho visa analisar a múltipla atuação da Controladoria Geral da União (CGU) dentro de nosso sistema político. Inicialmente centralizando o controle interno da Administração Pública Federal, recentemente esse órgão - além da defesa da legalidade nos procedimentos de controle, abarcando funções como o combate à corrupção, o monitoramento das políticas públicas e a promoção da transparência - tem, como aspecto mais inovador, desempenhado um importante papel na mobilização da sociedade civil, capacitando-a para o exercício da função de controle social dos governantes. Assim, o texto argumenta que a atuação desse órgão representa mais uma experiência na história política do país em que aparatos burocráticos do Estado atuam com grande protagonismo. Mas cabe frisar sua novidade, advinda do novo contexto democrático, que é exatamente a combinação da indução estatal com uma forte articulação com a sociedade.
\end{abstract}

PALAVRAS-CHAVE controle interno; controle social; democracia participativa; transparência; accountability.

Maria Rita Loureiro marita.loureiro@gmail.com

Doutora em sociologia pela USP; socióloga e professora do Departamento de Gestão Pública da FGV-EAESP e da FEA/USP

Fernando Luiz Abrucio fabrucio@gmail.com

Doutor em Ciência Política pela USP; cientista político e professor do Departamento de Gestão Pública da FGV-EAESP; coordenador do curso de Graduação em Administração Pública

Cecília Olivieri olivieri.cecilia@gmail.com

Doutora em Administração Pública e Governo pela FGV-EAESP; administradora pública e professora da Escola de Artes, Ciências e Humanidades da Universidade de São Paulo

\section{Marco Antonio Carvalho Teixeira marco.teixeira@fgv.br}

Doutor em Ciências Sociais (Política) pela PUC-SP; cientista político e professor do Departamento de Gestão Pública da FGV-EAESP; coordenador do curso de Graduação em Administração Pública

Artigo submetido no dia 30.05.2012 e aprovado em: 25.06.2012

ABSTRACT The study aims to examine the multiple actions of the Controladoria Geral da União (CGU) within our political system. Initially centralizing the internal control of the Federal Government, recently this body, in addition to defending the legality of the procedures for control, expanded its scope to other functions such as combating corruption, the monitoring of public policies, the promotion of transparency and, as an aspect more innovative, have played an important role in mobilizing civil society, enabling it to exercise the function of social control of the rulers. Thus, the text argues that the role of this organ is more experience in the political history of the country in which the bureaucratic apparatus of the state act with great leadership. But we should emphasize its novelty, arising out of the new democratic context, which is exactly the combination of induction state with a strong connection with society.

KEYWORDS Auditing, social control, participatory democracy, transparency, accountability.nt. 


\section{INTRODUÇÃo}

A Controladoria Geral da União (CGU) é criação recente no quadro institucional do país, estando prestes a completar uma década de existência em 2013. Ela centraliza o controle interno da Administração Pública Federal no Brasil e tem desempenhado papel de relevo na construção da ordem democrática brasileira, com atuação que vai além da de um mero órgão de controle interno, abarcando outras funções, como o combate à corrupção, o monitoramento das políticas públicas, a promoção da transparência, e, como aspecto mais inovador, tem um importante papel na mobilização da sociedade civil, o que a capacita para o exercício da função de controle social dos governantes.

A múltipla e inovadora estruturação da CGU é o objeto deste artigo, cujo intuito é descrever essa trajetória e mais especificamente analisar seu papel como fomentador do controle social, gerando um fenômeno que combina o ativismo estatal, característico da nossa história político-administrativa, com uma maior imersão junto a atores sociais. O ineditismo está exatamente neste último aspecto: um órgão burocrático estimulando o controle da sociedade sobre o próprio Estado.

A presente análise traça a trajetória histórica de ampliação de funções da CGU, dando particular ênfase à análise das experiências e iniciativas do fomento e fortalecimento do controle social. A relação especial que esse órgão de controle estabeleceu com os atores sociais tem implicações institucionais e teóricas pouco analisadas pela literatura. Institucionalmente, é a primeira vez que uma agência estatal de controle busca uma articulação tão forte com a sociedade para legitimar a agenda de promoção da transparência e do combate à corrupção. Teoricamente, esse modelo de atuação da CGU revela as imbricações entre Estado e sociedade nos processos participativos.
O texto a seguir está organizado da seguinte maneira. A primeira seção apresenta a trajetória do desenvolvimento institucional da CGU e o significado político desse processo e a segunda analisa o papel inédito da Controladoria na indução e fortalecimento do controle social, descrevendo uma série de experiências e iniciativas recentes. Ao final, é feita uma reflexão sobre o significado dessa experiência inovadora e seus impactos para a democracia brasileira.

\section{A TRAJETÓRIA POLÍTICO- INSTITUCIONAL DA CGU}

A criação da CGU representa inovação institucional no processo de controle dos governantes na democracia brasileira por várias razões. Primeiramente porque reorganizou o controle interno da Administração Pública Federal (APF), centralizando-o em um órgão com status ministerial. Até 1994 o controle interno se encontrava fragmentado como um departamento pouco eficiente, dentro de cada ministério, as Secretarias de Controle Interno, conhecidas como Cisets. Essa reorganização envolveu, além da centralização, a extensão das atividades também para o monitoramento das políticas públicas federais executadas nos entes subnacionais, por meio da fiscalização dos programas com financiamento da União (OLIVIERI, 2010). Entretanto, há que se ressaltar que o monitoramento das políticas públicas pela CGU ainda está em processo de consolidação.

Em segundo lugar, a criação da CGU consolida a ampliação das atividades de controle interno para a promoção da qualidade da gestão, indo além, portanto, do clássico controle da legalidade. Além disso, o que lhe tem dado grande visibilidade, a CGU se tornou a "agência anticorrupção do Brasil", responsável também pela luta contra a improbidade administrativa, por promover a 
transparência da APF e fomentar a ética e a integridade (CORREAA, 2011). ${ }^{1}$ Ademais, em quarto lugar, incentivou a difusão da prática do controle interno para os governos subnacionais.

E, por fim, mas não menos importante, a CGU passou a atuar como órgão indutor e fortalecedor do controle social, ou seja, da participação da sociedade civil no controle da administração pública, contribuindo decisivamente para a institucionalização desse processo através de várias iniciativas, como a formação técnica de conselheiros e a iniciativa da organização de conferências sobre controle social.

Para entender essa trajetória singular da CGU, cabe inicialmente constatar que a Constituição de 1988 reforçou os poderes das instituições de controle externo e interno, ambas definidas como guardiãs da legalidade e probidade na gestão pública, o que desencadeou processo gradativo de modernização das estruturas organizacionais desses órgãos, visando melhor qualificá-los para suas atribuições constitucionais. ${ }^{2}$

Esse fortalecimento configurou situação inédita em nossa história político-administrativa, uma vez que nossos dirigentes e gestores públicos têm, hoje, que se relacionar com três diferentes sistemas institucionais: a) o sistema representativo, ou seja, membros do poder legislativo; b) com o sistema participativo, ou seja, com os membros de conselhos de gestão ou controle social, participantes de conferências nacionais, estaduais ou municipais das diversas áreas de políticas públicas; c) e ainda com o sistema de controle, constituído por órgãos como os Tribunais de Contas, o Ministério Público, a CGU etc. (IPEA, 2011).

De fato, além de atuar no controle de irregularidades e da corrupção, a CGU também participa do processo de monitoramento das políticas públicas, envolvendo-se na promoção do desempenho e eficiência das políticas. Tais questões têm sido hoje, mais do que nunca, objeto de preocupação não só do Brasil, mas de todos os governos democráticos uma vez que eles assumem crescentes responsabilidades no provimento de serviços públicos a seus cidadãos, quase sempre em situação de restrição orçamentária.

Portanto, de um lado, as estruturas de controle no Brasil se fortalecem como resultado do desenvolvimento gradual e não linear das instituições democráticas, que requerem a responsabilização política contínua dos governantes e a respectiva prestação de contas de seus atos ou omissões. De outro lado, as instituições de controle em várias partes do mundo se fortalecem em decorrência das demandas sociais crescentes por mais eficiência e melhores resultados na gestão das políticas governamentais (POLLIT, 2008). Na verdade, em várias democracias, mesmo as mais antigas, como a inglesa, os órgãos de controle não só têm se expandido, inclusive para os níveis subnacionais ou governos locais, mas também têm recebido a orientação de que o controle não deve visar apenas o combate à corrupção, mas igualmente melhorar o desempenho da gestão pública. ${ }^{3}$

A estrutura atual da Controladoria, com a multiplicidade de atividades descrita acima, surgiu de forma incremental. No primeiro momento, entre 1994 e 2000, ainda antes do próprio surgimento da CGU, constituiu-se pela reorganização do controle interno e sua ampliação para o monitoramento das políticas públicas. A partir do governo Lula, emerge a visão da CGU como instituição catalizadora das políticas de promoção da transparência e combate à corrupção, como será indicado a seguir.

Conforme legislação criada no governo Lula (Medida Provisória $\mathrm{n}^{\circ} 103$, de $1^{\circ}$ de janeiro de 2003, Lei $\mathrm{n}^{\circ} 10.683$, de 28 de maio de 2003, e Lei $\mathrm{n}^{\circ}$ 11.204, de 2005), a Controladoria Geral da União liga-se à Presidência da República, com status de ministério e atribuições que envolvem a defesa do patrimônio público, o controle interno, a auditoria pública, a correição, a prevenção e o combate à corrupção, as atividades de ouvi- 
doria e o incremento da transparência da gestão no âmbito da Administração Pública Federal. Na realidade, sua constituição se deu pela reunião de órgãos que já existiam antes na $\mathrm{APF}$ - a Secretaria Federal de Controle Interno (SFC), do Ministério da Fazenda, e a Corregedoria Geral da União (CRG), criada em 2001, no governo Fernando Henrique Cardoso - e pela criação de duas novas áreas: a Secretaria de Prevenção da Corrupção e Informações Estratégicas, e a Ouvidoria Geral da União (OGU), que cuida das ações de ouvidoria (OLIVIERI, 2010).

Esse processo de centralização e fortalecimento do controle interno e a elevação da CGU ao status de ministério foram fundamentais para a superação da situação anterior de grande ineficiência do controle interno, que se devia ao arranjo institucional que prevaleceu até meados dos anos 1990, caracterizado pela descentralização dessa atividade no interior da APF. Existiam Secretarias De Controle Interno (Cisets) em cada ministério, e essa subordinação hierárquica ao ministro a quem deveriam controlar inviabilizava, na prática, uma atuação efetivamente de controle, auditoria e indicação, e correção de erros e irregularidades (OLIVIERI, 2010).

A rigor, a reforma do controle interno teve início bem antes do surgimento da CGU, e seu primeiro passo foi a criação da SFC no Ministério da Fazenda, em 1994. A secretaria desenvolveu, até 2000, um processo de reformulação das atividades de controle interno e de reorganização institucional. As atividades de auditoria e controle foram reformuladas para passarem a abranger não apenas a verificação da legalidade dos atos da APF, mas também a avaliação da eficiência e efetividade das políticas públicas, de modo a tornar-se um órgão parceiro do gestor na promoção da qualidade na gestão pública, e não apenas aquele que aponta e pune irregularidades (OLIVIERI, 2010).

Para tanto, foi necessária uma reforma organi- zacional que envolveu, basicamente, a centralização das atividades na SFC, com a decorrente extinção das Cisets, bem como a criação de unidades da SFC em todos os estados (as atuais Controladorias Regionais da União), para aprofundar e tornar mais eficiente a fiscalização dos órgãos da APF nos estados, bem como a fiscalização da utilização das verbas federais pelos municípios. Devido à grande descentralização das políticas públicas, ocorrida a partir dos anos 1980 e 1990, boa parte das políticas sociais implementadas nos municípios têm sido realizadas com recursos federais, cujo controle está a cargo de órgãos federais de controle externo e interno.

Mais recentemente, a CGU passou a fiscalizar também os estados, nas áreas em que executam verbas federais. Assim, o volume de recursos auditados aumentou, em decorrência principalmente da ampliação, nos anos 2000, do orçamento das políticas federais de infraestrutura, realizadas predominantemente por meio de repasses financeiros da União aos estados e municípios, os quais se responsabilizam por realizar obras viárias, de saneamento e habitacionais.

Em 2001 foi criada a Corregedoria Geral da União, que absorveu as atividades de controle interno no ano seguinte, por meio da incorporação da SFC. Esse processo se constituiu, em boa parte, pela reação do governo Fernando Henrique Cardoso a denúncias de corrupção no final de seu segundo mandato, com o objetivo de demonstrar empenho na criação e fortalecimento de instituições de controle.

Todavia, o governo Lula marca uma nova era para a CGU, caracterizada pela ampliação de suas atividades e grande fortalecimento institucional. Já no primeiro dia de seu mandato, em janeiro de 2003, uma medida provisória alterou o nome da Corregedoria Geral da União para Controladoria Geral da União, sacramentando o novo escopo da organização, que foi explicitado no discurso de posse do primeiro ministro chefe da Controladoria: 
A confiança do presidente Lula e do nosso partido me entregaram a direção desta casa, até ontem chamada de Corregedoria Geral da União. Foi bom que o ato normativo hoje publicado, pelo novo governo, tenha substituído sua denominação para a de Controladoria Geral da União. [...]

Não gostava do título Corregedoria. A lembrança, desde os tempos coloniais, da figura do corregedormor, sempre agindo para o serviço de eI-rei e seu séquito, na proteção de normas conservadoras, quase imutáveis, por sobre a estrutura das relações escravocratas e, posteriormente, das relações oligárquicas, excludentes - toda essa memória não me agradava. Na Controladoria, cuidaremos, sim, de correição e punições, como atos resultantes da violação dos princípios básicos da Lei e da vida republicana, princípios que precisarão ser mantidos, prestigiados e consolidados. Penso, que sabe?! poderemos, um pouco mais adiante, conseguir no Legislativo uma nomenclatura mais explicitamente democrática, que encerre, nela mesma, a mensagem valorosa da cidadania, da dignidade da condição humana, que é a essência do Estado Democrático de Direito. Nesse caso, então, chegaríamos à ideia do chefe da Controladoria chamarse ministro de Estado do Controle e da Transparência. Para o compromisso com a defesa do dinheiro público, que é oriundo dos tributos cobrados aos cidadãos, e com a transparência - a mais plena - que viabilize a total informação de seu destino, como e por que os serviços públicos e as políticas públicas são realizados. (Trechos do discurso de posse de WALDIR PIRES, 2003, grifos nossos.)

Nessa fala, Waldir Pires, que dirigiu a CGU no primeiro mandato de Lula, deixou explícita a nova visão do governo sobre a atuação da CGU de consubstanciar a busca da plenitude da cidadania e do Estado Democrático de Direito, ou seja, romper com a tradição do exercício do controle como instrumento de imposição pelos governantes de "normas conservadoras e relações excludentes" e associar a atividade de controle às demandas e princípios democráticos: bom uso do dinheiro público e transparência.

$\mathrm{Na}$ verdade, é importante frisar que esse mo- mento representou um ponto de inflexão importante na curta história institucional da CGU, quando foram vencidas resistências internas e externas à ampliação de suas atribuições para além do controle interno. ${ }^{4}$ A tônica estabelecida a partir daí permanece até hoje, tendo sido garantida pela continuidade na administração da CGU (o atual dirigente, Jorge Hage, foi o principal auxiliar de Waldir Pires e o substituiu a partir de 2006). Essa continuidade se expressa ainda na promoção de importantes iniciativas da CGU desde 2003: o Programa de Fiscalização por meio de Sorteios Públicos, o Portal da Transparência, o Programa Olho Vivo no Dinheiro Público e a Conferência Nacional sobre Transparência e Controle Social.

A primeira iniciativa do ministro Waldir Pires para implementar essa nova visão do governo para a CGU, isto é, de promover relações governamentais democráticas e transparentes, foi a substituição do Programa de Fiscalização nos Municípios - iniciado pela SFC em 1995 e continuado pela corregedoria no governo Fernando Henrique Cardoso - pelo Programa de Fiscalização a partir de Sorteios Públicos. Essas mudanças, realizadas em 2003, visaram tornar a fiscalização já realizada pelos analistas da CGU nos municípios um exemplo de promoção de transparência da gestão pública e de combate à corrupção.

Os efeitos desse programa em termos de visibilidade e aprovação pública foram muito grandes, devido à extensa publicidade promovida pela CGU aos sorteios dos municípios a serem fiscalizados e à inédita divulgação dos relatórios da fiscalização realizada em cada um. As principais mudanças realizadas pelo Programa de Fiscalização por Sorteios foram as seguintes: alteração no foco da fiscalização nos municípios (da gestão do programa federal que repassava os recursos para a gestão do prefeito); a instituição de ampla publicidade ao programa (garantida pela realização dos sorteios pela Caixa Econômica Federal, nos mesmos moldes do sorteio da Loteria Federal, e 
pela publicação dos relatórios identificados por município no site da CGU na internet); e a substituição do foco no aperfeiçoamento da gestão dos ministérios para o combate à corrupção nos municípios.

A mudança no foco da fiscalização foi substantiva. Até 2003, a fiscalização nos municípios tinha como objetivo principal produzir informações sobre o desempenho dos programas federais no nível nacional. A fiscalização nos municípios se restringia a alguns programas escolhidos em função de sua relevância orçamentária, e os municípios eram selecionados com base em critérios estatísticos de forma a constituir uma amostra aleatória de tamanho suficiente para se produzir um diagnóstico no nível nacional da qualidade da gestão de cada ministério. A partir de então, o critério de seleção dos municípios passa a ser o sorteio, e são fiscalizados todos os programas federais implementados no município sorteado. A seleção por sorteio tinha como objetivos criar em todos os municípios a expectativa de serem sorteados e, portanto, fiscalizados (e assim estimular a preocupação, em todos, com a qualidade e probidade da gestão), além de impedir qualquer alegação de que a seleção fosse feita com objetivo de perseguição ou retaliação política.

A publicação dos relatórios no site da CGU também foi uma grande mudança no programa, porque até então os relatórios eram divulgados, mas sem a identificação dos municípios fiscalizados. Desde 2003, os relatórios são divulgados em arquivos de fácil acesso (em formato pdf), identificados com o nome da cidade, e, apesar de relativamente sucinto, cada relatório apresenta de forma muito clara as irregularidades identificadas na fiscalização (e a publicação ocorre após o prefeito ter acesso ao seu conteúdo e oportunidade de retificar informações incorretas).

A reação dos prefeitos foi grande, com ocorrência isolada de eventos de ameaças veladas a equipes de analistas da CGU em visita a municípios e de resistência de funcionários municipais a entregarem documentos oficiais para os analistas, e até com a propositura de mandado de segurança no STJ contra o programa pela Federação dos Municípios do Estado do Maranhão e pela União das Prefeituras da Bahia. Elas alegaram que a CGU não tinha competência para fiscalizar municípios, que a publicação dos relatórios configurava "lesão moral e política" aos prefeitos e que a fiscalização caracterizava perseguição política por parte de Waldir Pires (um dos principais adversários políticos de Antônio Carlos Magalhães na Bahia). O STJ decidiu unanimemente contra os municípios e a favor da continuidade do programa.

Finalmente, a terceira mudança foi a substituição do foco no aperfeiçoamento da gestão dos ministérios para o combate à corrupção nos municípios, e se efetivou na criação de novos instrumentos de fiscalização e novas parcerias entre a CGU, a Polícia Federal e o Ministério Público. As operações especiais, em que funcionários da CGU agiam conjuntamente com agentes da Polícia Federal e do Ministério Público, foram cruciais para a identificação de esquemas de corrupção como, por exemplo, a "máfia das ambulâncias" (desvio de recursos federais na compra de ambulâncias pelos municípios).

A reação política decorrente da atuação da CGU foi tão grande que em 2005 o Senado solicitou ao TCU uma auditoria sobre a Controladoria, especialmente sobre o Programa de Fiscalização por Sorteios. A conclusão do TCU foi que a CGU desempenhava adequadamente suas funções, e que o programa foi executado de acordo com a legislação. Em outras palavras, o Programa de Sorteios permitiu à CGU alterar o direcionamento do planejamento das ações de controle e cumprir seus principais objetivos (combater a corrupção, universalizar a expectativa de controle, aproximar a CGU da sociedade civil e fortalecer o controle social)

Aos poucos, o Programa de Fiscalização por 
sorteios foi expandido. A partir de 2004, incluiu os estados nos sorteios, e desde 2007 as capitais e os grandes municípios (com mais de 500 mil habitantes) passaram também a ser fiscalizados (eles estavam excluídos dos sorteios devido à restrição da capacidade da CGU de dispor de funcionários para fiscalizar estruturas governamentais maiores). Um dos seus principais resultados concretos foi a inédita divulgação de informações sobre a gestão municipal. Com base nessas informações, foram realizados trabalhos científicos que nos permitem conhecer muito mais sobre a gestão e a política municipais brasileiras, e cuja realização seria praticamente impossível sem o trabalho da CGU, uma vez que muito dificilmente uma equipe de pesquisadores teria recursos suficientes para construir uma série de dados tão extensa quanto essa. Para se ter uma ideia mais clara, até 2009, segundo o site da CGU, haviam sido fiscalizados 1.811 municípios (32,5\% do total), e o volume de recursos auditados correspondeu a quase $\mathrm{R} \$ 14$ bilhões.

Hoje sabemos que a principal causa das irregularidades encontradas nos municípios auditados até agora é a má gestão e não a corrupção. Erros devidos à falta de qualificação do pessoal levam a irregularidades no uso dos recursos federais pelos municípios, e em poucos casos os erros podem ser enquadrados como efetivo desvio de dinheiro (BIDERMAN; AVELINO, 2010). Em muitos casos, há desvio de função, como, por exemplo, dinheiro enviado para ser gasto na compra de remédios é usado na compra de material escolar, o que é uma irregularidade do ponto de vista legal, mas não caracteriza corrupção. Além disso, ainda é pequena a capacidade dos ministérios para resolver os problemas que ocorrem na implementação de suas políticas em nível municipal de governo. A partir da análise dos relatórios da CGU, Marcos Mendes (2004) identificou os principais problemas na gestão do Fundef (atual Fundeb) nos municípios, bem como a inação do Ministério da Educação em criar instrumentos para resolvê-los em âmbito nacional.

Esses trabalhos demonstram, portanto, que do ponto de vista administrativo é necessário promover a qualidade da gestão federal e municipal para o melhor uso dos recursos públicos. Isso não implica dizer que o problema da corrupção não existe, mas reconhecer que o problema dos municípios não se refere apenas a condutas ilegais, mas principalmente diz respeito à capacitação para gerir as políticas e extrair o máximo resultado dos recursos escassos, sejam locais ou federais.

Outros trabalhos analisaram os efeitos da publicidade desses relatórios sobre os resultados da eleição municipal. Ferraz et alii (2008) mostraram que os prefeitos que se candidataram à reeleição e que tinham tido suas administrações mal avaliadas no relatório da CGU tiveram mais dificuldade para se reeleger. Ou seja, a disponibilidade de informação sobre a qualidade da gestão dos prefeitos tem efeitos políticos concretos, pois a população tende a não reeleger prefeitos mal avaliados. Note-se que o objetivo da CGU não é fazer uma avaliação propriamente dita da gestão dos prefeitos, mas apenas apontar irregularidades na gestão de recursos federais - mas é claro que a população associará as irregularidades com a sensação que tem sobre a qualidade dos serviços.

O Programa de Fiscalização por Sorteios alcançou, portanto, os objetivos desejados pelo governo de promover a transparência das ações governamentais (como veremos a seguir, a gestão federal também ficou mais exposta, através da divulgação de dados no Portal da Transparência) e houve efeito mensurável sobre a responsabilização dos governantes do nível municipal em função dos resultados das fiscalizações da CGU.

Por outro lado, o Programa de Fiscalização por Sorteios também permitiu à CGU se aproximar da gestão municipal e perceber as fragilidades da atuação dos conselhos municipais, especialmente quanto a sua capacidade de efetuar o controle so- 
cial, ou seja, identificar problemas na gestão municipal e alertar as instituições de controle como tribunais de contas e Ministério Público. Dessa experiência surgiu o Programa Olho Vivo no Dinheiro Público, destinado à capacitação técnica dos conselheiros, como vemos mais adiante.

\section{A CGU COMO INDUTORA E FORTALECEDORA DO CONTROLE SOCIAL}

Nesta parte do texto, procura-se mostrar como a CGU, órgão da burocracia governamental, inicialmente constituída como instrumento de controle interno, assume papel de destaque na indução da própria atividade de controle social, realizando duas atividades tradicionalmente assumidas pelas instituições políticas representativas, sem, entretanto, pretender substituí-las: 1) organização política da sociedade civil por meio de fóruns ou órgãos colegiados; 2) capacitação de membros ou lideranças da sociedade civil para o exercício da cidadania.

É interessante relembrar aqui que isso está claramente explicitado em texto publicado pela Revista da CGU, quando cita o primeiro dirigente da CGU no governo Lula como o inspirador original desse movimento, num momento em que ainda não havia na instituição uma reflexão sobre isso:

A decisão política de incluir na agenda de ações da CGU o enfrentamento do problema da ausência das condições necessárias ao exercício do controle social por parte da sociedade deve ser creditada ao exministro Waldir Pires - pessoa que tem a sua história marcada pela militância em movimentos sociais de luta pela democratização do país. (SANTANA, 2009, p. 47).

Três iniciativas principais da CGU na organização da sociedade civil e em sua capacitação técni- ca para o exercício do controle social serão aqui enfatizadas: a criação do Conselho da Transparência Pública e Combate à Corrupção (CTPCC), a criação do Programa de Olho Vivo no Dinheiro Público e a convocação e organização da Conferência Nacional sobre Transparência e Controle Social (Consocial).

Antes de analisar especificamente a constituição do CTPCC, cabe indicar que desde 2004 foi disponibilizado na internet pela CGU o Portal da Transparência. Mais do que o uso de uma nova tecnologia eletrônica, a criação desse portal representa medida de considerável importância política, considerando ter ele permitido o acesso livre não só da imprensa, mas de todos os cidadãos brasileiros, a milhares de informações relativas ao governo federal, aí incluindo obras, licitações, políticas públicas, inclusive os beneficiários dos programas sociais, despesas governamentais de vários tipos, salários e diárias de servidores públicos, transferências para estados e municípios num total de 800 milhões de registros sobre mais de 5 mil ações governamentais (www.portaltransparencia.gov.br).

Segundo indicações da própria CGU, a criação do portal visou aumentar a transparência da gestão pública e permitir que o cidadão acompanhe como o dinheiro público está sendo utilizado e ajude a fiscalizá-lo. Qualquer cidadão, sem necessidade de senha, pode acompanhar os gastos do governo federal. Desde sua instalação, em 2004, o número de visitantes tem crescido: iniciou-se com pouco mais de 64 mil e atingiu em 2010 a cifra de quase 4 milhões de visitantes anuais. Tudo isso fez com que o Portal da Transparência tenha se tornado referência internacional, garantindo reconhecimento e prêmios ao Brasil pelos incentivos ao controle social (www.portaltransparencia. gov.br).

Com relação ao Conselho da Transparência Pública e do Combate à Corrupção, trata-se de um colegiado consultivo ligado à CGU, com o obje- 
tivo de sugerir e debater medidas de aperfeiçoamento dos métodos e sistemas de controle dos recursos públicos, de promoção da transparência na gestão pública e de combate à corrupção e à impunidade, como informa o site institucional da Controladoria. Ao tomar a iniciativa de criá-lo, a CGU orientou-se por princípios de accountability frente à sociedade civil, distribuindo seus membros de forma paritária entre ela e os representantes do Estado (LINHARES NETO, 2009).

Assim, o CTPCC está composto de um total de 20 membros, sendo 10 representantes de instituições estatais e 10, de instituições da sociedade civil. Dentro os representantes estatais, estão: CGU, Advocacia Geral da União, Tribunal de Contas da União, do Ministério Público da União, da Comissão de Ética Pública da Presidência da República, da Casa Civil, do Ministério da Fazenda, do Ministério da Justiça, do Ministério do Planejamento e Orçamento e do Ministério das Relações Exteriores. Dentre os representantes da sociedade civil, estão: Ordem dos Advogados do Brasil, Associação Brasileira de Imprensa, Conferência Nacional dos Bispos do Brasil, Associação de Igrejas Evangélicas, Associação Brasileira de Organizações Não Governamentais (ABONG), sindicatos patronais e trabalhistas, Transparência Brasil, Instituto Ethos e um cidadão brasileiro com atuação notória.

Algumas questões teóricas podem ser suscitadas a partir da atuação desse conselho. A primeira refere-se à articulação entre Estado e instituições democráticas de representação e participação. ${ }^{5} \mathrm{~A}$ atuação do CTPCC traz, na verdade, exemplos, um bem-sucedido, outro não tanto, de um processo de articulação entre uma agência burocrática governamental (CGU), uma instituição participativa (a CTPCC) e o Congresso. O exemplo de um resultado bem-sucedido dessa articulação pode ser encontrado no caso da lei de acesso à informação, que foi incluída na pauta das discussões do CTPCC desde 2005. Segundo Linhares Neto
(2009), depois de numerosos debates sobre esse tema na comissão, ele foi enviado à Casa Civil da Presidência da República e, depois de revisto, foi agregado ao Projeto de Lei n ${ }^{\circ}$ 5.228/200, enviado ao Congresso e recentemente aprovado como a Lei de Acesso à Informação (maio de 2012).

Já o exemplo não tão bem-sucedido, em termos de seu resultado, mas não em termos do processo de articulação entre os sistemas institucionais mencionados, refere-se ao tema de conflito de interesses. Seu objetivo era instituir um período mínimo prévio para que os altos dirigentes públicos pudessem assumir cargos na iniciativa privada. Como se trata de questão importante para o controle da corrupção e a accountability governamental, foi criado dentro do CTPCC, já em 2005, um grupo de trabalho encarregado dessa discussão que também elaborou um anteprojeto encaminhado à Casa Civil da Presidência da República para em seguida ser submetido à consulta pública. Desde o final de 2006, um projeto de lei sobre esse assunto foi para o Congresso Nacional. Todavia, ele foi barrado por lideranças do Partido dos Democratas, que alegaram que a comissão de mérito não havia realizado audiência pública, engavetando assim o assunto (LINHARES NETO, 2011, p. 32-33).

Em suma, tais relatos evidenciam situações antes inéditas na história político-administrativa brasileira de articulação entre aparato de controle e instituições democráticas participativas e representativas cujas implicações merecem ser objeto de reflexão mais aprofundada pela literatura da ciência política e da administração pública.

A segunda questão teórica a destacar na comissão paritária Estado/sociedade civil no controle social refere-se às iniciativas fomentadoras da CGU de criação de novas instituições estatais e societais. Cabe relatar que nasceu do CTPCC, como iniciativa conjunta da CGU e do Instituto Ethos, um cadastro nacional de empresas comprometidas com a ética e a integridade. Esse ca- 
dastro, denominado "Empresa Pró-Ética", avalia e divulga as empresas voluntariamente engajadas na construção de um ambiente de integridade e confiança nas relações comerciais, inclusive naquelas que envolvem o setor público. Ele pretende dar visibilidade às empresas que compartilham a ideia de que a corrupção é um problema que deve ser prevenido e combatido não só pelo governo, mas também pelo setor privado e pela sociedade, e fazer com que as empresas, ao se cadastrar, assumam o compromisso público e voluntário, perante o governo e a sociedade, de adotar medidas para prevenir e combater a corrupção dentro de sua instituição, em favor da ética nos negócio. ${ }^{6}$

Em outras palavras, tem-se aqui uma clara ação estimuladora do Estado para que a sociedade se organize para exercer o controle das próprias atividades governamentais.

Mais recentemente (por meio do Decreto n. ${ }^{\circ}$ 7.592, de 28 de outubro de 2011), a CGU levou adiante sua ação empreendedora de ampliação da transparência da administração pública brasileira criando também o Cadastro de Entidades Privadas Sem Fins Lucrativos Impedidas, isto é, o Cepim. Trata-se de uma inovação organizacional mais simples porque se refere apenas à formação de um banco de informações mantido por ela, a partir de dados fornecidos pelos órgãos e entidades da Administração Pública Federal. Ele tem por objetivo consolidar e divulgar a relação das entidades privadas sem fins lucrativos que estão impedidas de celebrar convênios, contratos de repasse ou termos de parceria com a Administração Pública Federal. Segundo o próprio site da CGU, o cadastro facilita a consulta por nomes ou CNPJ da entidade, indica o motivo do impedimento, tudo em linguagem técnica acessível, servindo de fonte de referência aos órgãos do governo para prevenir a corrupção, sendo também ferramenta de transparência para a sociedade em geral. Portanto, a ação de fomento aqui se configura pela simples agilidade de reunir informações e dispo- nibilizá-las.

Também o Programa Olho Vivo no Dinheiro Público representa ação fomentadora por parte da CGU, mas de outro tipo. Seu ativismo aqui se refere à formação de capacidade técnica na sociedade civil para o exercício da função do controle social (LINHARES NETO, 2009). Esse programa nasceu, durante a implantação de outro programa da CGU, o Programa de Fiscalização de Municípios por Sorteios Públicos, em 2003. Nessa ocasião, constatou-se que inúmeras irregularidades encontradas nos municípios que executavam obras com recursos financeiros transferidos pela União eram decorrentes de fraudes ou corrupção, mas que outra parte também significativa era resultante da falta de preparo ou de capacitação dos servidores municipais responsáveis pela execução dos programas.

Em decorrência disso, a CGU se mobilizou internamente e iniciou o Projeto de Mobilização e Capacitação de Agentes Públicos, Conselheiros Municipais e Lideranças Locais, o que acabou levando à institucionalização do Programa Olho Vivo em 2004. Conforme balanço desse programa, em apenas quatro anos de atividades, foram realizados 124 reuniões de formação de quadros de mais de mil municípios brasileiros, envolvendo, no total, mais de 15 mil conselheiros municipais, agentes públicos e lideranças locais (SANTANA, 2009, p. 44).

Apesar do balanço positivo quando se olha para o alcance das atividades já desenvolvidas pelo Programa Olho Vivo, Santana (2009, p. 56) também faz alerta para seus limites. O primeiro refere-se ao fato de os cursos ocorrerem em apenas dois ou três dias, o que considera tempo insuficiente para que os cidadãos se qualifiquem tanto de forma técnica como de maneira política para o exercício do controle social.

O segundo nos leva a uma questão ainda mais complexa e que Santana chama de "limitações históricas impostas pela cultura secular da não 
participação", obstáculo que considera superável ao longo do tempo, uma vez que, assim como o Olho Vivo, existe um conjunto de outras experiências de aprendizagem democrática que estão contribuindo para incluir na cultura política brasileira o controle social como um instrumento de adensamento da democracia, o que abre a expectativa de mudanças.

Por fim, Santana ainda destaca que a diversificação dos cursos, a ampliação de parcerias com organizações da sociedade civil, assim como a indução e o fortalecimento de uma grande rede que inclua organizações locais, regionais e nacional, em torno de ações educativas com as mesmas finalidades verificadas no Olho Vivo, serão vitais para que o programa continue percorrendo um caminho por ele considerado exitoso.

Com relação à Conferência Nacional sobre Transparência e Controle Social (Consocial), cabe indicar que ela também surgiu no seio da CGU no momento em que esta realizava seu $1^{\circ}$ Seminário Nacional sobre Controle Social, em setembro de 2009, que já havia mobilizado mais de 500 participantes. A partir daí, ela foi convocada oficialmente pelo presidente da República em dezembro de 2010. E teve grande importância porque, desde então, foram feitas no país 837 conferências municipais e 186 regionais, além de conferências livres, realizadas por organizações não governamentais, de estudantes, associações de moradores e de outros grupos organizados. A preparação da conferência, que mobilizou cerca de 1 milhão de pessoas nas etapas municipais, regionais e estaduais (por volta de 2,5 mil conferências), favoreceu posteriormente a implementação da nova lei de acesso à informação na agenda pública.

Entre os 1.200 delegados presentes na Consocial, realizada em maio de 2012 em Brasília, havia representantes da sociedade civil, do poder públicos dos conselhos de políticas públicas, preocupados em discutir diretrizes de atuação para assegurar a efetividade de políticas públicas de promoção da transparência e da participação social. $^{7}$

Dentre os quatro eixos temáticos, o que mais recebeu propostas foi o que trata das diretrizes para prevenção e combate à corrupção: 5.736 (28\%). Já o eixo temático sobre mecanismos de controle social, engajamento e capacitação da sociedade para o controle da gestão pública recebeu 5.122 propostas (25\%). O número de sugestões apresentadas em relação à promoção da transparência pública e acesso à informação e dados públicos recebeu 4.917 propostas (24\%); e o quarto eixo, referente à atuação dos conselhos de políticas públicas como instâncias de controle, 4.712 (23\%).

Dois pontos principais chamam particularmente a atenção nos resultados da Consocial.

O primeiro refere-se ao fato de que o financiamento exclusivamente público de campanhas eleitorais foi a recomendação que mais votos recebeu, com 80 propostas votadas eletronicamente por aproximadamente 1,1 mil delegados que participaram do evento.Conforme a proposta, um valor limitado e igual para todos os partidos deve ser estabelecido a partir de um fundo público, "sendo passível de suspensão dos direitos políticos aquele que usufruir de financiamentos privados e com multa para empresas, pessoas físicas e/ou entidades que financiarem essas campanhas". A sugestão acrescenta que "deve haver efetiva fiscalização e redução do número de partidos políticos, com dados disponibilizados nos portais de transparência" (www.consocial.cgu.gov.br).

Segundo, além do combate à corrupção, outro assunto em destaque na Consocial foi a Lei de Acesso à Informação, que, segundo uma das recomendações aprovadas, deve ser aplicada "com severidade e rigor como forma de auxiliar o acesso à informação e combater a corrupção". Diz o documento: "Para tanto, os governos devem implantar sistemas informacionais com códigos livres, padronizados e interligados entre os seus 
setores; criar em suas páginas links de acesso às contas das despesas e investimentos municipais de forma simples e inteligível aos cidadãos, onde se publiquem em tempo real toda a tramitação dos processos em tribunais de contas e controladorias, assim como dos atos administrativos em geral" (www.consocial.cgu.gov.br).

$\mathrm{Na}$ opinião da diretora de Prevenção da Corrupção da Controladoria Geral da União (CGU), Vânia Vieira, "é uma feliz coincidência" que a Consocial tenha ocorrido na semana em que entrou em vigor a Lei de Acesso à Informação. Para ela, a divulgação da lei e a mobilização da sociedade são consideradas estratégicas pelo governo. "Pode ter portal de transparência, dado aberto na internet e conselhos funcionando, mas é fundamental que haja participação. A transparência só vai adquirir potência de modificar [a cultura política do país] na medida em que houver participação social", acrescenta Pedro Pontual, diretor de Participação Social da Secretaria Geral da Presidência da República (www.consocial.cgu.gov.br).

Esse dois pontos mostram claramente outro papel político exercido pela CGU, além dos já mencionados anteriormente (defesa da legalidade, combate à corrupção promoção da eficiência das políticas públicas e capacitação para o controle social), o de mobilização da sociedade para a defesa de uma causa, não só a garantia da Lei de Acesso à Informação, mas também o financiamento público de campanhas eleitorais. Trata-se de um papel político tradicionalmente exercido por partidos políticos, associações da sociedade civil ou grupos específicos de advocacy, mas que está sendo realizado por um órgão burocrático do Estado, e mais especificamente, da área de controle.

Note-se que a singularidade desse caso não tem o intuito, aqui, de fazer uma crítica conservadora a um "uso político" da CGU, nem de dizer que sua atuação é feita em detrimento de outras instituições clássicas da democracia, já que a Contro- ladoria faz articulações com organizações autônomas, as quais aceitam participar e até incentivam outras a fazê-lo, além de os próprios partidos mandarem seus militantes para a Consocial. Em vez de um olhar dicotômico, o que se pretende realçar é que há novas combinações na democracia brasileira entre o sistema representativo, o participativo e o sistema de controle. E o que é mais importante: é necessário haver uma reflexão ainda mais aprofundada sobre o potencial e os desafios desse novo arranjo político.

\section{CONSIDERAÇÕES FINAIS: IMPLICAÇÕES PARA A DEMOCRACIA BRASILEIRA}

Ao ampliar o foco de sua atuação para além do controle interno, a CGU tornou clara, para os seus membros, a ligação dos problemas da gestão pública com os do controle democrático. No que se refere à gestão, o aprofundamento dos mecanismos de transparência e auditoria, tais como a fiscalização por sorteios públicos, por exemplo, fez com que a CGU constatasse que as dificuldades dos governos locais fossem bem além da corrupção - embora esta nunca tenha sido esquecida. Por isso, começou a atuar mais sobre a melhoria das gestões públicas e em particular sobre a capacitação técnica dos gestores locais.

Em todo esse processo, o mais importante foi que os dirigentes da CGU perceberam claramente que estavam atuando dentro de um novo contexto democrático e de grande valorização das instituições participativas (inclusive em termos constitucionais), e, portanto, seria preciso envolver atores sociais para conseguir, a um só tempo, combater a corrupção e capacitar a sociedade para cobrar mais dos governos. Em suma, seria preciso agir em prol de uma pedagogia cidadã para construir governos com melhor desempenho. 
Ao adotar esse caminho, a CGU se tornou mais porosa e imbricada (embedded) com a sociedade, conforme a denominação clássica de Peter Evans (1993). Isso aumentou sua legitimidade social e seu poder dentro do governo, em processo similar ao que ocorreu com outras burocracias (MARTINS, 1976; NUNES, 1997). Se esse não é um fenômeno novo, de um lado, por outro revela ineditismo, na medida em que gerou uma nova combinação entre sistemas representativos, participativos e de controle.

É claro que há o perigo de a CGU exacerbar o seu poder, adotando a postura que o Ministério Público teve na década de 1990, quando procurou ser o paladino da justiça e se colocou como o representante por excelência da sociedade (cf. ARANTES, 2002). Embora exista essa possibilidade, o que se constata na pesquisa é um caminho diferente: houve uma aproximação com atores sociais e outras instituições, criando espaços de parceria ou atuando em processos de capacitação dos cidadãos. Em vez de insulada e "salvacionista", como muitas burocracias atuaram historicamente no país, a ação da CGU tem sido mais aberta e entrelaçada.

A descoberta dessa nova prática, com feições inéditas para um órgão burocrático de controle, abre uma nova agenda de pesquisa na área de Administração Pública no Brasil. O que se constata, com o presente trabalho, é que a defesa isolada do sistema representativo ou do participativo já não faz mais sentido, tanto do ponto de vista teórico quanto no plano normativo, porque as interações são mais dinâmicas e ricas, inclusive agora contempladas com a entrada em cena dos órgãos de controle. O caso da CGU é expressivo dessa nova realidade, pois ela não atua mais apenas como controladora, mas também como ativadora das energias políticas e sociais da cidadania.

\section{NOTAS}

1 Segundo Corrêa (2011), integridade pública é conceito desenvolvido pela OCDE (Organização para a Cooperação e o Desenvolvimento Econômicos) e se refere à aplicação de valores e normas aceitas nas práticas cotidianas das organizações do setor público. Assim, o objetivo de um sistema de integridade seria tornar a corrupção, ou seja, a prática ilícita, atividade de alto risco e baixo retorno. (p. 165).

${ }^{2}$ Conforme o artigo 70 da Constituição de 1988, o controle divide-se em externo e interno: o primeiro é efetuado pelo Congresso Nacional, com o auxílio do Tribunal de Contas da União, e o segundo está a cargo do "sistema de controle interno de cada poder". Com a criação da Controladoria Geral da União, em 2003, esse órgão passou a se incumbir da responsabilidade pelo controle interno da Administração Pública Federal, inclusive do controle dos recursos federais repassados aos governos subnacionais.

${ }^{3}$ Esse trecho, embora relativo à situação inglesa, exprime bem a nova realidade das relações entre controle e gestão pública: "É nosso objetivo que as autoridades locais percebam, cada vez mais, seus auditores como uma fonte de ideias e sugestões construtivas, e não apenas como uma checagem retrospectiva da legalidade e uso apropriado dos recursos públicos. [...] Nós acreditamos que uma relação cooperativa e colaborativa entre auditores e autoridades locais pode auxiliar imensamente a busca por economia, eficiência e efetividade. Obviamente os auditores jamais perderão suas funções regulatórias. Eles devem, antes de tudo, garantir que o gasto público seja apropriado e esteja de acordo com a lei. Mas o seu papel vai muito além de uma definição estreita de auditoria de questões gerenciais, e mudanças positivas [nesse sentido] podem ser alcançadas onde a cooperação surgir" (RADFORD, 1991, p. 918).

${ }^{4}$ Menção especial deve ser feita às pressões vindas de setores conservadores do Congresso Nacional que defendiam que a CGU não deveria fiscalizar os municípios brasileiros, como afirmou o senador da Bahia Cesar Borges, em pronunciamento no dia 11/12/2003, criticando o suposto "uso da CGU para fins políticos" (SANTANA, 2009, p. 48).

${ }^{5}$ A respeito da discussão teórica sobre a articulação entre instituições democráticas participativas e representativas, ver os textos de Urbinati (2006), Pinto (2009), Loureiro (2009). Sobre estudos empíricos relativos ao tema, pode-se citar também a interessante pesquisa recente de Pogrebinsky e Santos (2011).

${ }^{6}$ Ver trechos da ata de reunião desse conselho, realizada em maio de 2010, também publicada em site na internet. Nessa reunião, sugeriram-se também medidas para garantir a transparência dos projetos para a Copa de 2014 e para as Olimpíadas de 2016. 
${ }^{7}$ Ela se organizou em quatro eixos temáticos: 1) promoção da transparência pública e acesso à informação e dados públicos; 2) mecanismos de controle social, engajamento e capacitação da sociedade para o controle da gestão pública; 3) atuação dos conselhos de políticas públicas como instâncias de controle; 4) diretrizes para a prevenção e combate à corrupção.

\section{REFERÊNCIAS}

ARANTES, Rogério Bastos. Ministério Público e Política no Brasil. São Paulo: Sumaré/Educ, 2002.

BIDERMAN, Ciro; AVELINO, George. A descentralização brasileira em perspectiva comparada: gestão das transferências federais para os municípios. Relatório de Pesquisa. São Paulo: CEPESP/FGV, 2010 .

CORREA, Izabela M. Sistema de integridade: avanços e agenda de ação para a Administração Pública Federal. In: AVRITZER, L.; FILGUEIRAS, F. (Orgs.). Corrupção e sistema político no Brasil. Rio de Janeiro: Civilização Brasileira, 2011.

CORREA, Izabela M.; CAPANEMA, Renato de Oliveira (2009). O papel da Controladoria Geral da União no fortalecimento do Sistema Nacional de Integridade no Brasil, texto apresentado no XIV Congreso Internacional del CLAD sobre La Reforma del Estado y de La Administración Pública, Salvador de Bahia, Brasil, outubro, 2009

EVANS, PETER. Estado como problema e solução. Revista Lua Nova. n. 28-29, 1993

FERRAZ, C.; FINAN, F. Exposing corrupt politicians: the effects of Brazil's publicly released audits on electoral outcomes. Quarterly Journal of Economics, v. 123, n. 2, p. 703-745, 2008.

LINHARES NETO, Damásio A.; BRITO, Eveline M. Incidência da atuação do Conselho da Transparência Pública e combate à corrupção no processo de accountability federal. Revista da CGU, Brasília, Presidência da República, Controladoria Geral da União, ano VI, n. 9, jun. 2011

LOUREIRO, Maria Rita. Interpretações contemporâneas da representação. Revista Brasileira de Ciência Política, v. 1, p. 63-93, 2009.

LOUREIRO, Maria Rita; TEIXEIRA, Marco Antonio Carvalho;
MORAES, Tiago Cacique. Democratização e reforma do Estado: o desenvolvimento institucional dos tribunais de contas no Brasil contemporâneo. Revista da Administração Pública, Rio de Janeiro, v. 43 , n. 4 , p. $739-772$, ago. 2009

MARTINS, Luciano. Estado capitalista e burocracia no Brasil pós-64. Rio de Janeiro: Paz e Terra, 1985.

MENDES, Marcos. Análise das irregularidades na administração municipal do Fundef: constatações do programa de fiscalização a partir de sorteios públicos da Controladoria Geral da União. Transparência Brasil. 2004. Disponível no site <www. transparencia.org.br>.

NUNES, EDSON. A gramática política do Brasil. Rio de Janeiro: Jorge Zahar; Brasília: Enap, 1999.

OLIVIERI, CECÍLIA. A lógica política do controle interno - O monitoramento das políticas públicas no presidencialismo brasileiro. São Paulo: Annablume, 2010.

PINTO, C. R. J. Espaços deliberativos e a questão da representação. RBCS, São Paulo, v. 19, n. 54, fev. 2004.

POLLIT, CRISTOPHER et alii. Desempenho ou Legalidade? Auditoria operacional e de gestão pública em cinco países. Belo Horizonte: Fórum, 2008.

RADFORD, M. Auditing for change: local government and the audit commission. The Modern Law Review, v. 54, n. 6, Law and Accountancy, p. 912-932, Nov. 1991.

SANTANA, ANTÔNIO. E. S. Programa Olho Vivo no Dinheiro Público: limites e possibilidades de fomento do controle social. Revista da CGU, Brasília: Presidência da República, Controladoria Geral da União, ano IV, n. 6, set. 2009

SPINELLI, M. V. C. O sistema de controle interno do Executivo federal em perspectiva comparada. Revista da CGU, Brasília: Presidência da República, Controladoria Geral da União, ano IV, n. 6 , set. 2009

POGREBINSCHI, THAMY; SANTOS, F. G. M. Participação como representação: o impacto das conferências nacionais de políticas públicas no Congresso Nacional. Dados (Rio de Janeiro. Impresso), Revista de Ciências Sociais, v. 54, p. 21-47, 2011.

URBINATI, NADIA. Representative Democracy: Principles \& Genealogy. Chicago: The University of Chicago Press. 2006. 